\section{The influence of vocalization activity} on short-term recall

\author{
PHILLIP M. TELL and BRENDAN X. VOSS \\ Florida Technological University, Orlando, Fla. 32816
}

The Peterson distractor technique was used to investigate the effect of vocalization activity on short-term recall. Ss were required to voice or silently read to-be-remembered consonant trigrams and were tested for recall at retention intervals up to $12.6 \mathrm{sec}$. It was found that the auditory input resulting from vocalization activity was a facilitating source of information in short-term recall when compared with silent reading of trigrams. The findings further indicate that vocalization activity has its most beneficial effects at the shorter retention intervals.

Much interest has recently developed concerning the influence of auditory and articulatory factors in short-term recall. For example, a number of findings have indicated that aural presentation of materials facilitates recall over short periods of time, as compared with nonvoiced visually presented materials (e.g., Cooley \& McNulty, 1967; Grant \& McCormack, 1970; Murdock, 1966, 1967). Cooley and McNulty, using the Peterson distractor technique (Peterson \& Peterson, 1959), found that recall of aurally presented trigrams was superior to visually presented items over short retention intervals. Grant \& McCormack (1970), using a similar manipulation, found that aural presentation is consistently superior to visual presentation at all retention intervals up to $18 \mathrm{sec}$. Their data also indicate that presentation mode has its major influence at the shorter retention intervals. These studies provide considerable evidence that short-term recall can be facilitated by auditory input.

A number of studies have also shown that voicing of the visually presented materials provides superior recall to silent reading of them (e.g., Murray, 1965a, b; Tell, 1970). Murray (1965b) presented lists of eight consonants visually. Ss were instructed to read the items silently, mouth them silently, whisper them, or say them aloud. A modified free-recall procedure was used with Ss having only to specify the position of the item. At fast presentation rates (4 letters/second), overall recall scores were found to increase monotonically with degree of vocalization. Tell (1970), using the distractor technique, investigated the influence of vocalization activity at various retention intervals up to $6.3 \mathrm{sec}$. He found that recall can be manipulated directly by varying the intensity of auditory input resulting from vocalization activity. The influence of vocalization activity varied with the retention interval tested, and these influences appeared to decrease somewhat at the longest retention interval.
The present study used the distractor technique to investigate the influence of vocalization activity on the recall of consonant trigrams over varying retention intervals. Its purpose was to determine if the effects of vocalization activity were comparable to those of presentation modality (e.g., Grant \& McCormack, 1970) at short as well as at longer retention intervals. It was hypothesized that: (1) The auditory input resulting from vocalization activity would be a facilitating source of information in short-term recall as compared with silent reading of materials. (2) The influence of vocalization activity would have its most beneficial effects at the short retention intervals; at longer retention intervals the effects attributable to vocalization activity would be diminished.

\section{SUBJECTS}

The Ss were 60 undergraduates at Florida Technological University. All Ss were tested individually and received course credit for participating in the experiment.

\section{MATERIALS AND APPARATUS}

Twenty-eight consonant trigrams were selected from the Witmer norms in Appendix B of Underwood \& Schulz (1960) in such a way as to minimize association value, intertrigram, and intratrigram similarity. Repeated occurrences of any consonant were separated by at least two trigrams. Four of the 28 trigrams served as practice items and were not used in analysis of data or counterbalancing of conditions. These trigrams were photographed on $35-\mathrm{mm}$ film and mounted in slide holders.

Blue gelatin filters mounted in slides marked the onset of each trial. A series of three question marks presented on slides cued the onset of the recall interval.

The trigrams, blue ready slides, and recall slides were projected by means of a Kodak Carousel 800 projector. Series of two-digit numbers for the interpolated task were filmed on $16 \cdot \mathrm{mm}$ motion picture film and were projected with a Durning Animatic film-strip projector. Both of these projectors were operated by tone pulses placed on magnetic tape by the use of electromechanical programming equipment.

\section{DESIGN AND PROCEDURE}

Using the Peterson distractor technique, Ss attempted to retain consonant trigrams while performing an interpolated task. The interpolated task involved the presentation of digit pairs at the rate of $0.9 \mathrm{sec}$ per pair, and all Ss were tested after $1,3,5,8,11$, and 14 pairs of digits. Thus, the retention intervals used were $0.9,2.7,4.5,7.2,9.9$, and $12.6 \mathrm{sec}$. The interpolated activity required classifying each member of the digit pair verbally as "odd" or "even," from left to right.

All Ss received 28 trials; the first 4 were practice, the rest were test trials. The order of trigram presentation was the same for all Ss. Each $S$ was required to vocalize the trigrams on half the test trials and to read them silently on the other half. The order of presentation activity was counterbalanced, so that $30 \mathrm{Ss}$ vocalized the first 12 test trials and silently read the remaining 12 . The other 30 had this ordering reversed. The first 4 practice trials were presented in the same manner as the initial test trials.

A 6 by 6 Latin square determined the ordering of the six retention intervals within the 24 test trials. Each $S$ received retention intervals determined by four rows of the Latin square. Each retention interval followed all other retention intervals an equal number of times and never followed itself.

Briefly, a single test trial proceeded in the following manner: A blue ready light illuminated the screen for $1 \mathrm{sec}$. Following this by $.75 \mathrm{sec}$, a trigram was presented on the screen for $.75 \mathrm{sec}$, during which time the $S$ either read it aloud or silently. After the presentation of each trigram, Ss were tested at one of the six retention intervals. Three question marks appeared after the last digit pair was removed from the screen.

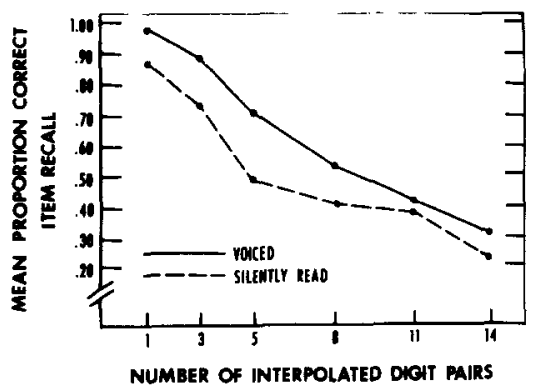

Fig. 1. Mean proportion items correctly recalled as a function of presentation activity and retention interval. 
These remained on the screen for $10 \mathrm{sec}$, while $S$ attempted to recall the trigram. A 10 -sec intertrial rest interval followed before the start of the next trial.

\section{RESULTS AND DISCUSSION}

The data of each $S$ were scored in terms of the number of consonants correctly recalled, regardless of whether they appeared in the correct intratrigram position. With low-association-value trigrams, it appears that the item score is the most meaningful and sensitive unit of analysis (Wickelgren, 1965). Results are not presented for ordered scores because in all important respects they are in close agreement with the item scores.

An overall analysis of variance indicated that the effects of presentation activity (voiced vs silently read), $F(1,59)=65.55$, $\mathrm{p}<.001$, retention interval, $F(5,295)=132.38, \quad p<.001$, and the Presentation Activity by Retention Interval interaction, $F(5,295)=2.93, p<.05$, were all significant. As can be seen in Fig. 1, recall performance decreased over retention intervals for both presentation activities. Further, it can be seen that voiced presentation conditions were superior to silently read conditions at all retention intervals tested. It was hypothesized that vocalization activity would be a facilitating source of information as compared to silent reading, and this is supported by the significant main effect of presentation activity.

In order to determine if vocalization activity was more beneficial at the shorter retention intervals than at the longer ones, the data from the six retention intervals was dichotomized into shorter retention intervals (1, 3, and 5 digit pairs) and longer ones $(8,11$, and 14 digit pairs). An analysis of variance was performed on these condensed data. The most relevant finding from this analysis was the highly significant Presentation Activity by Retention Interval interaction, $F(1,59)=106.81, p<.001$. This interaction indicates that vocalization activity has its major influence at these shorter retention intervals and lends support to the second hypothesis. These findings also parallel those of Grant \& McCormack (1970), who found that the type of presentation condition (auditory vs visual) had its major effect at the shorter retention intervals. The similarity of these findings may indicate that the variable of underlying importance is the auditory input which results from either auditory presentation or vocalization activity.

\section{REFERENCES}

COOLEY, R. K., \& MCNULTY, J. A. Recall of individual CCC trigrams over short intervals of time as a function of mode of presentation. Psychonomic Science, 1967, 9, 543-544.
GRANT, K. W., \& McCORMACK, P. D. Auditory and visual siort-term memory with successive presentation both modalities. Psychonomic Science, 1970, 17, 341-342.

MURDOCK, B. B. Visual and auditory stores in short-term memory. Quarterly Journal of Experimental Psychology, 1966, 18, 206-211.

MLRDOCK, B. B. Auditory and visual stores in short-term memory. Acta Psychologica, 1967, 27, 316-324.

MURRAY, D. J. The effect of white noise upon the recall of vocalized lists. Canadian Joumal of Psychology, 1965a, 19, 333-345.

MURRAY, D. J. Vocalization at presentation, auditory presentation and immediate recall Nature, 1965b, 207, 1011-1012.
PETERSON, L. R., \& PETERSON, M. J. Short term retention of individual verbal items. Journal of Experimental Psychology, 1959, 58, 193-198.

TELL, P. M. The effect of intensity of vocalization on short-term memory. Paper presented at the meeting of the Southeastern Psychological Association, Louisville, April 1970.

UNDERWOOD, B. J., \& SCHULZ, R. W. Meaningfulness and verbal learning. Chicago: Lippincott, 1960.

WICKELGREN, W. A. Acoustic similarity and intrusion errors in short-term memory. Journal of Experimental Psychology, 1965, 70, 102-108.

\title{
Serial task structure and the doctrine of remote associations
}

\author{
N. C. ELLIS \\ Texas A \& M University, College Station, Tex. 77843
}

A series of studies by Slamecka (1964) provided impetus for developing three criteria to test the validity of anticipatory and perseverative errors. Since these criteria were met by conditions of a previous study (Ellis \& Manning, 1967), supplementary data were collected, combined with the earlier data, and reexamined. In addition to finding support for Slamecka's concept of item positioning, it was determined that intraitem structure also affects frequency and distribution of serial learning errors. Comparing these results with expectancies predicted by remote association theory cast additional doubt on the validity of anticipatory and perseverative errors.

An examination of new data combined with data from a previously reported study (Ellis \& Manning, 1967) is presented in this report. Although the original study did not include this objective, the author feels that when combined with the supplementary data, results of this new analysis justify presentation. The results are particularly relevant since they throw additional light on a classical concept of psychology, namely the doctrine of remote associations.

Briefly, this doctrine asserts that during serial learning, associative bonds develop between items other than adjacent items. When an association exists between a stimulus and an item which has occurred earlier in the sequence, it is called a perseverative error. A bond is called an anticipatory error if the stimulus is linked with an item which is further ahead in the sequence. Anticipatory errors are said to outnumber perseverative errors, and the frequency of each is inversely related to degree of remoteness.

Previous research generally supported these ideas until the report of a series of studies by Slamecka (1964). He concluded that the doctrine of remote associations was of doubtful validity, and he presented alternative explanations for data resulting from typical methods of study. He made a strong case for "perception of patterning" and "differential practice."

Slamecka's dismissal of anticipatory and perseverative errors, however, is not as convincing. In his discussion he rejects the assumption that intralist errors are remote associations. They are more likely, he says, the result of two things operating in the experimental task: (1) acquisition of items, per se, and (2) fixing of their position in the list using self-generated sequential or spatial symbols. The apparent difficulty is that Slamecka argues from data (Table 4, p. 72) that are identical to data of early theorists. It occurred to this author that a more substantive test was required before one could dismiss the validity of anticipatory and perseverative errors.

Criteria for such a test would include: (1) reducing the task of item acquisition, (2) relaxing the requirement for item positioning, and (3) retaining the serial nature of the task. It occurred to this author that these conditions had in fact been met in his earlier study. Criteria 2 and 3 were met by construction of a series of stimuli having a particular kind of underlying structure. This structure was used to define serial learning tasks in which the initial stimulus was varied from trial to 